\title{
THE RELATIONS BETWEEN POLYCYCLIC AROMATIC HYDROCARBONS EXPOSURE AND 1-OHP LEVELS AS A BIOMARKER OF THE EXPOSURE
} Zuzana Klöslová1, Marek Drímal², Karol Balog³, Kvetoslava Koppová4, Jarmila Dubajová5

${ }^{1}$ European Chemicals Agency, Helsinki, Finland

${ }^{2}$ Faculty of Natural Sciences, Matej Bel University, Banská Bystrica, Slovak Republic

${ }^{3}$ Faculty of Materials Science and Technology in Trnava, Slovak University of Technology in Bratislava, Trnava, Slovak Republic

${ }^{4}$ Faculty of Health in Banská Bystrica, Slovak Medical University in Bratislava, Banská Bystrica, Slovak Republic

${ }^{5}$ Regional Public Health Authority, Nitra, Slovak Republic

\section{SUMMARY}

Background and Aim: Polycyclic aromatic hydrocarbons (PAHs) are the products of incomplete combustion or pyrolysis of various organic materials. Their ubiquity in the environment leads to measurable levels of exposure. However, the exposure varies strongly between different regions in Europe. Some PAHs with four or more rings are suspected to be human carcinogens. Therefore, the occupational and/or environmental exposure to PAHs may cause a significant health risk. The aim of the study was to evaluate current levels of PAH exposure in defined groups of workers.

Methods: The industrial sites selected in this survey involved PAHs originating from coal tar pitch, carbon black, bitumen, and rubber fumes. Based on the historical data, the sites were expected to exhibit quantifiable levels of exposure to PAHs. The total study population consisted of 139 persons: 108 workers ( 85 males and 23 females) occupationally exposed in aluminium production, the production of graphite electrodes, road construction, or the rubber forming industry and 31 control individuals in two groups.

Results: The highest concentrations - 8-hour time-weighted average (TWA) levels (sum of 16 components according to the EPA list), as expected, were found in the aluminium production plant $\left(55.15 \mu \mathrm{g} \cdot \mathrm{m}^{-3}\right)$ and production of graphite electrodes $\left(54.25 \mu \mathrm{g} \cdot \mathrm{m}^{-3}\right)$. The lowest concentrations were found in personal air samples of road construction workers $\left(1.93 \mu \mathrm{g} \cdot \mathrm{m}^{-3}\right)$. The concentrations of 1 -hydroxypyrene as a pyrene metabolite (1-OHP) in the urine of the exposed group of workers were found in levels $0.74 \mu \mathrm{mol}^{\mathrm{mol}}{ }^{-1}$ creatinine before the exposure and $2.27 \mu \mathrm{mol} . \mathrm{mol}^{-1} \mathrm{creatinine}$ after the exposure (arithmetic mean values). 1-OHP concentrations in post-shift urine samples were highly correlated with the total airborne PAHs concentrations and pyrene concentrations in air. The correlation coefficients $\left(r_{s}\right)$ between 1-OHP concentration and pyrene or total PAHs in air were 0.710 and $0.752(p<0.05)$. This statistical analysis confirmed the effect of the occupational exposure to PAHs and pyrene on body burden in workers. However, a modifying effect of gender, smoking habits, dietary intake, genetically modified metabolism, and the use of medication on the toxicokinetics of pyrene was not determined as significant.

Conclusion: Based on the results a strong correlation between the concentration of 1-OHP in urine as an exposure biomarker and the concentration of pyrene or PAH was affirmed.

Key words: polycyclic aromatic hydrocarbons (PAHs), 1-hydroxypyrene (1-OHP), benzo(a)pyrene (BaP), occupational exposure

Address for correspondence: M. Drímal, Faculty of Natural Sciences, Matej Bel University, Tajovského 40, 97556 Banská Bystrica, Slovak Republic. E-mail: marek.drimal@umb.sk

http://dx.doi.org/10.21101/cejph.a4179

\section{INTRODUCTION}

Polycyclic aromatic hydrocarbons (PAHs) are produced during incomplete combustion of organic substances. Many of them are well known as human carcinogens. These are widespread contaminants discharged to the environment mostly from industrial sources. PAHs include chemicals that are typically found together in groups of two or more substances. PAHs are solid substances and vary in appearance from colourless to white and pale yellow-green. PAHs are created by incomplete combustion of a wide spectrum of materials like coal, oils, wood, and garbage. They can also be found in smoked meat or tobacco smoke. The main urban source of PAHs is motor vehicle traffic. Therefore, people may be exposed to PAHs through multiple media, including air, soil, food, water, and because of their occupation (1). Based on their different chemical properties, two main classes of PAHs can be recognized; the two-three ring and the four-six ring compounds. The first class is characterized by lower molecular weight (128-166 amu) and lower boiling point (bp $217-295^{\circ} \mathrm{C}$ ), while the second class is characterized by higher molecular weight and boiling point $\left(202-278 \mathrm{amu}, \mathrm{bp}>375^{\circ} \mathrm{C}\right)$ (2). Environmental properties of individual PAHs are quite dif- 
ferent. They are persistent; they can stay in the environment for long periods of time. The majority of PAHs are not very soluble in water, but some of them can turn into vapour very easily. The two ring compounds when present at higher levels in a PAHs mixture may have irritative effects and cause respiratory diseases. A notable exception in this class is naphthalene, the smaller and more volatile $\mathrm{PAH}$, that was recently classified as a possible carcinogen to humans (class 2B) (3). Some of the four-six ring PAHs have been classified as possible or probable carcinogen to humans (classes 2B and 2A) by the International Agency for Research on Cancer (4).

Human population is exposed to PAHs from several sources in occupational and residential environment (5).

Occupational exposure of workers by inhalation can be found in several industrial processes. High levels were reported during aluminium production, coal gasification, coke production, and iron and steel founding. Another source of PAHs is bitumen, used in road construction, especially asphalting.

Since the 1940s, the exposure of workers to PAHs has been assessed by measurements of air in the workplace. In the 1970s personal air sampling replaced static air sampling.

The level of PAH metabolites in urine can be used as a biological indicator of exposure to PAH. Studies are especially available on the excretion of 1-hydroxypyrene (1-OHP) in the urine.

Because pyrene is the major component in PAHs mixtures and its urinary metabolites (1-OHP and 1-OH pyrene glucuronide) are usually abundant and relatively easy to measure, human exposure is usually assessed by monitoring 1-hydroxypyrene (1-OHP) in urine samples (6).

Urinary 1-OHP is a metabolite of pyrene, which is always present in the mixture of PAHs in exposure sites. Therefore, measuring 1-OHP serves not only as an indicator of pyrene, but that of exposure to mixture of PAHs as well (7).

Recently, Yamano et al. studied personal exposure of coke oven workers by measuring 15 airborne PAHs. They calculated the carcinogenic potency of the exposure and concluded that urinary 1-hydroxypyrene, among 10 other urinary hydroxylated PAH-metabolites, was the most comprehensive carcinogenic biomarker of exposure to PAHs (8). Käfferlein et al. showed, based on studies with DNA damage in workers exposed to benzo(a) pyrene $(\mathrm{BaP})$, that 1-hydroxypyrene is the preferred parameter to assess exposure to PAHs at the workplace among a series of urinary PAH-metabolites (9).

The results of this paper are based on a short-term monitoring study of occupational exposure to airborne PAHs at four manufacturing plants in Slovakia and two control groups. This study focused on the analysis of PAHs in personal air samples and of urinary 1-OHP.

\section{MATERIALS AND METHODS}

\section{Study Population}

We investigated four plants which were suspected to produce PAHs. These sites were chosen based on the request of the Slovak State Health Service. The aluminium production plant (plant 1) focuses on the production of aluminium $(\mathrm{Al})$ by electrolysis of mixture $\mathrm{Al}_{2} \mathrm{O}_{3} / \mathrm{Na}_{3} \mathrm{AlF}_{6}$ (cryolite), the plant producing carbon materials (plant 2) produces carbon and graphite semi-products. The third plant produces rubber products as O-rings, silent blocks, and gaskets (plant 3 ). The last one is a road building company - asphalt production and asphalting (plant 4). The study population of 139 persons ( 99 males and 40 females) consisted of 108 exposed persons ( 85 males and 23 females) from the above mentioned plants, and 31 in two control groups.

The control group consisted of two groups. The first group (3 males and 6 females) comprised workers of the respective plants occupationally not exposed to PAHs to assess the influence of parameters of health and lifestyle. The mean age of this group was 42.6 years. The second control group comprised employees of the Regional Public Health Authority (RPHA) in Banská Bystrica without the risk of occupational exposure. This group was chosen in order to assess the sensitivity of biomonitoring of the content of 1-OH-pyrene in urine. This group consisted of 22 subjects (11 males and 11 females) with a mean age of 39.6 years. The control groups were studied in a manner analogous to the exposed groups.

Exposed workers from the individual plants were divided into groups in each single plant according to the assumed level of exposure in order to obtain more homogenous exposure levels of subgroups in comparison to the total number of exposed persons in individual plants. The correct selection of subgroups, number of workers in each subgroup and frequency of sampling were verified by a critical study of occupational activity and by pilot analyses of PAHs in workplace atmosphere.

\section{Airborne PAHs}

Personal samples for occupational exposure and fixed-point samples of workplace atmosphere were collected simultaneously. The personal samples were collected using mini-pumps SKC 224 - PCEX3. Air samplers, used to assess personal exposure to airborne PAHs, consisted of a Teflon filter to collect PAHs on particulate matter, connected in series with a XAD-2 sorbent tube to collect PAHs present in the vapour phase. The pumps were calibrated with flow rates of $2 \mathrm{dm}^{3} \cdot \mathrm{min}^{-1}$ with a minimum sampling time of 6 hours. PAHs absorbed on personal samplers were desorbed with acetonitrile and analyzed by HighPerformance Liquid Chromatography (HPLC) with fluorometric detection (10).

Fixed point samples were provided by a TVR 17 pump with fiber glass and polyurethane foam (PUF) filters. The total inhalable particles (below $100 \mu \mathrm{m}$ ) and vapours were collected. The samplers were used for 5.5 hours with flow rates of $20 \mathrm{dm}^{3}$. $\mathrm{min}^{-1}$. The PUF were extracted in a Soxhlet's extractor for 6 hours, and fiber-glass filters were extracted by ultrasonic bath (20 min). Both types of extracts were combined, and after adding cyclohexane were analyzed by HPLC with photometric and fluorometric detection.

Fluorometric detection enables selective determination of 15 polyaromates - naphthalene, acenaphthene, fluorene, phenanthrene, anthracene, fluoranthene, pyrene, benz(a)anthracene, chrysene, benzo(b)fluoranthene, benzo(k)fluoranthene, benzo(a) pyrene, dibenz(a,h)anthracene, benzo(g,h,i)perylene, and indenopyrene. Acenaphthylene (non emitting fluorescent radiation) was determined by photometry detection.

The sum of PAHs was calculated after that and pyrene result was also used for determination of exposure input. 


\section{PAHs as 1-OHP in Urine}

Urine samples were collected before work, after the weekend and then after three days of exposure (at the end of the third work day), or at the end of the work week. All subjects provided approximately $35-40 \mathrm{ml}$ of urine samples that were protected from light and stored at $-20^{\circ} \mathrm{C}$ until the analyses. In addition, each involved person responded to a brief questionnaire that gives information about drug usage, nutrition, smoking, and occupational history.

The determination of 1-OHP was based on the enzymatic hydrolysis of conjugated metabolites and their extraction. After that, the hydrolyzed urine sample was applied to a $\mathrm{C} 18$ reverse phase cartridge which had been washed with $5 \mathrm{ml}$ methanol and $5 \mathrm{ml}$ distilled water. The sample was passed through the cartridge and after that washed by 5 or $10 \mathrm{ml}$ distilled water. The retained solutes were eluted with $5 \mathrm{ml}$ methanol. The solvent was evaporated at $50-60^{\circ} \mathrm{C}$. Afterwards the sample was transferred into a capped vial and analyzed by HPLC with fluorometric detection. Urinary 1-OHP concentrations were adjusted by creatinine concentrations and were expressed as $\mu$ mol.mol ${ }^{-1}$ creatinine.

\section{Statistical Analysis for PAHs and 1-OHP}

The descriptive characteristics - mean, geometric mean, harmonic mean, median, range, interquartile range, percentiles, standard deviation, skewness, and kurtosis were used to describe measured data. Data measured under the quantitation limit were adjusted to $50 \%$ of the quantitation limit (11).

PAHs concentrations and 1-OHP values were log transformed to assure normal distribution (after use of the Shapiro-Wilk test). The Grubb's test was applied in the next step to test outlying values in single groups. The Wilcoxon signed-rank test was used to evaluate changes in concentrations of 1-OHP before and after exposure time. The relationship between PAHs, BaP and pyrene in workplace atmosphere and 1-OHP in urine was examined using the nonparametric Spearman's rank correlation coefficient $\left(\mathrm{r}_{\mathrm{s}}\right)$ test. The two hypotheses were defined: H1 - exposure to PAHs, pyrene and $\mathrm{BaP}$ in workplace atmosphere affects 1-OHP levels in urine after three-day exposure. $\mathrm{H} 0$ - exposure to $\mathrm{PAHs}$, pyrene and $\mathrm{BaP}$ in workplace atmosphere does not affect 1-OHP levels in urine after three-day exposure (null hypothesis). To test the statistical significant difference among pair exposure groups, the multiple analysis of variance (ANOVA) was used. In all the cases the selected level of significance was set at $\alpha=0.05$. All analyses were conducted by using STATA statistical software version 8.1 (College Station, TX USA).

For the assessment of differences in concentration levels of 1-hydroxypyrene in the exposed group based on gender, age and smoking, Wilcoxon signed-rank test have been used. In order to establish the complex impact assessment and interactions of the above mentioned factors (age, gender and smoking) for assessment of fundamental relationship of exposure PAH - level of 1-hydroxypyrene in the urine - MANOVA (Multivariate Analysis of Variance) multidimensional dispersion analysis has been used, which is actually an extension of ANOVA dispersion analysis.

\section{RESULTS}

Descriptive statistics for PAHs, $\mathrm{BaP}$ and 1-OHP as a biomarker of PAH exposure are presented in Table 1. Figures 1 and 2 show the descriptive characteristics of $\mathrm{BaP}$ and 1-OHP.

The highest concentrations of PAHs were observed in the plant 1 , especially in carbon materials production section. The highest level of total PAHs, $777.7 \mu \mathrm{g} . \mathrm{m}^{-3}$, was reported at the black pitch smelter located in the plant 1 . High concentrations $41.3 \mu \mathrm{g} . \mathrm{m}^{-3}$ and $137.0 \mu \mathrm{g} . \mathrm{m}^{-3}$ were also measured in personnel samples of the mixing room workers. These values exceeded relevant standards

Table 1. Workplace atmosphere concentrations of PAHs and BaP and urinary 1-OHP

\begin{tabular}{|c|c|c|c|c|c|c|c|}
\hline Plants & $\mathrm{n}$ & $\begin{array}{c}\text { Median } \\
\mu \mathrm{g} \cdot \mathrm{m}^{-3}\end{array}$ & $\begin{array}{l}\text { Mean } \\
\mu g \cdot m^{-3}\end{array}$ & $\begin{array}{l}\text { Range } \\
\mu g \cdot m^{-3}\end{array}$ & $\begin{array}{c}q_{1}\left(25^{\text {th }} \text { percentile }\right) \\
\mu \mathrm{g} \cdot \mathrm{m}^{-3}\end{array}$ & $\begin{array}{c}q_{3}\left(75^{\text {th }} \text { percentile }\right) \\
\mu g \cdot m^{-3}\end{array}$ & $\begin{array}{c}\text { SD } \\
\mu g \cdot m^{-3} \\
\end{array}$ \\
\hline \multicolumn{8}{|l|}{ PAHs } \\
\hline Plant 1 & 19 & 0.50 & 55.15 & $0.05-777.73$ & 0.09 & 22.55 & 173.17 \\
\hline Plant 2 & 66 & 44.74 & 54.25 & $0.15-147.50$ & 24.63 & 84.43 & 40.17 \\
\hline Plant 3 & 27 & 17.89 & 25.11 & $0.23-87.50$ & 6.51 & 33.25 & 26.13 \\
\hline Plant 4 & 7 & 0.79 & 1.93 & $0.16-5.60$ & 0.61 & 2.86 & 1.82 \\
\hline \multicolumn{8}{|l|}{ BaP } \\
\hline Plant 1 & 19 & 0.04 & 0.19 & $0.01-2.00$ & 0.03 & 0.16 & 0.43 \\
\hline Plant 2 & 64 & 1.25 & 1.31 & $0.01-3.18$ & 0.45 & 2.1 & 0.92 \\
\hline Plant 3 & 27 & 0.46 & 0.63 & $0.02-2.27$ & 0.16 & 0.97 & 0.65 \\
\hline Plant 4 & 7 & 0.04 & 0.10 & $0.01-0.28$ & 0.03 & 0.14 & 0.09 \\
\hline \multicolumn{2}{|l|}{ 1-OHP } & $\mu \mathrm{mol} . \mathrm{mol}^{-1} \mathrm{creat}$ & $\mu \mathrm{mol} . \mathrm{mol}^{-1}$ creat. & $\mu \mathrm{mol} . \mathrm{mol}^{-1}$ creat. & $\mu \mathrm{mol} . \mathrm{mol}^{-1} \mathrm{creat}$ & $\mu \mathrm{mol} . \mathrm{mol}^{-1} \mathrm{creat}$ & $\mu g \cdot m^{-3}$ \\
\hline Plant 1 & 19 & 1.20 & 4.99 & $0.00-24.40$ & 0.95 & 4.95 & 6.53 \\
\hline Plant 2 & 65 & 2.85 & 2.59 & $0.11-4.57$ & 1.45 & 3.65 & 1.22 \\
\hline Plant 3 & 27 & 1.78 & 1.93 & $0.98-3.46$ & 1.42 & 2.25 & 0.66 \\
\hline Plant 4 & 7 & 1.32 & 1.37 & $1.05-2.04$ & 1.19 & 1.40 & 0.30 \\
\hline
\end{tabular}

The number of samples is not equal for PAHs, BaP and 1-OHP because some workers have more than 1 working place. It was necessary to measure more than one air concentration. 


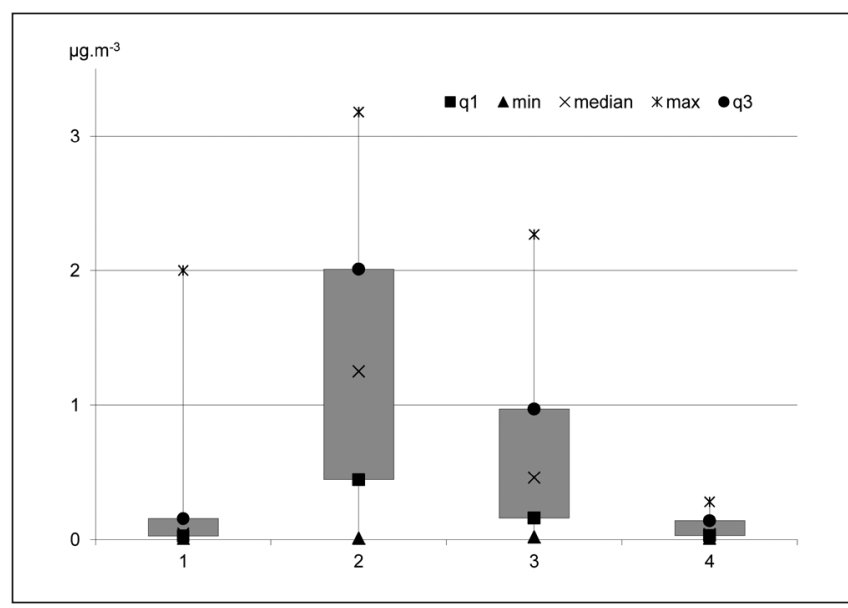

Fig. 1. Descriptive characteristics of $\mathrm{BaP}$.

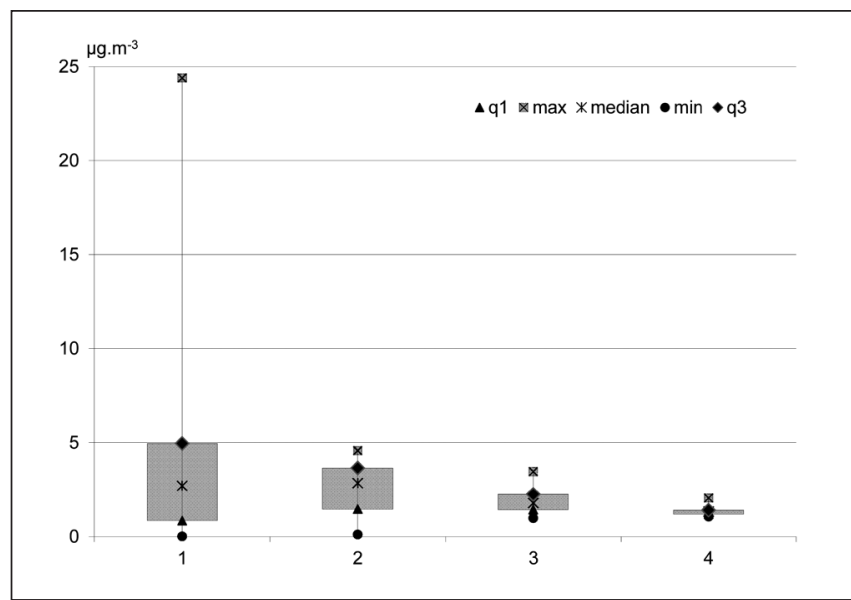

Fig. 2. Descriptive characteristics of 1-OHP.

- time-weighted average (REL-TWA) of the US National Institute for Occupational Safety and Health (NIOSH) $100 \mu \mathrm{g} . \mathrm{m}^{-3}$ and the Occupational Safety and Health Association standard $200 \mu \mathrm{g} . \mathrm{m}^{-3}$. High levels of PAHs with a mean concentration of $92.98 \mu \mathrm{g} . \mathrm{m}^{-3}$ were analyzed in personnel samples of production of carbon material workers, especially in the mixing of raw materials section. High concentrations with a mean of $70.4 \mu \mathrm{g} . \mathrm{m}^{-3}$ were measured in the raw material pressroom. Lower values were reported in the plant 4 - values in the range from $0.2-5.6 \mu \mathrm{g} . \mathrm{m}^{-3}$. Good air dispersion conditions at the time the measurements were taken could explain this fact. The highest concentration of BaP, as most distinguished member of PAHs, was observed in the plant 2. The mean concentration for all samples was $1.31 \mu \mathrm{g} \cdot \mathrm{m}^{-3}$ but in the raw material mixing room it was $2.14 \mu \mathrm{g} \cdot \mathrm{m}^{-3}$.

Implying from the measurement results, the highest individual concentrations of 1-OHP after 3-day exposure were set in plant 1 - the production of carbon materials at pitch furnace operator $\left(24.4 \mu \mathrm{mol} . \mathrm{mol}^{-1}\right.$ creatinine $)$ and at the carbon mass dosage operator (19.8 $\mu \mathrm{mol} . \mathrm{mol}^{-1}$ creatinine). On the basis of these two particular values the average value (arithmetic mean) was 7.8 $\mu$ mol. $\mathrm{mol}^{-1}$ creatinine. Relatively high concentrations of 1-OHP were also found in the urine samples from workers in the plant 2. Individual exposure values were in the interval from $0.1-4.6$ $\mu$ mol.mol ${ }^{-1}$ creatinine. The average value (arithmetic mean) was $2.6 \mu \mathrm{mol} . \mathrm{mol}^{-1}$ creatinine.
In the urine of the control groups, the values of 1-OHP ranged from $0.07-1.25 \mu \mathrm{mol} . \mathrm{mol}^{-1}$ creatinine in control group 1, and from 0.08-0.90 $\mu \mathrm{mol} . \mathrm{mol}^{-1}$ creatinine in control group 2.

\section{Temporal Changes of 1-hydroxypyrene}

Based on the results in Table 2 (after eliminating the extreme values), the 95 percentile of the concentrations of 1-hydroxypyrene as a pyrene metabolite in the urine of the exposed group of workers were found at level $1.26 \mu \mathrm{mol} . \mathrm{mol}^{-1}$ creatinine before

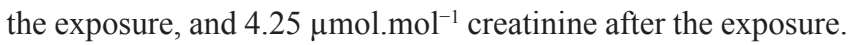
Values of arithmetic mean and median were 0.74 and $0.91 \mu \mathrm{mol}$. $\mathrm{mol}^{-1}$ before and 2.27, $2.15 \mu \mathrm{mol} . \mathrm{mol}^{-1}$ after exposure.

The Wilcoxon signed-rank test was used to evaluate the changes in the concentration levels of 1-hydroxypyrene in the exposed group before and after exposure. The goal of testing was to determine significance of the difference between the two medians. Based on the result $(\mathrm{p}<0.05)$, the null hypothesis on the compatibility of set groups was rejected. The hypothesis on the existence of statistically significant difference in the levels of 1-OHP in urine samples before and after a 3-day exposure was accepted.

\section{Analysis of Relations between External Exposure and Internal Dose}

With the goal of determining mutual relations and/or potential dependence between the concentrations of PAHs and pyrene in the workroom air and the concentrations of 1-OHP in the urine of the exposed persons, distribution analysis ANOVA (Analysis of Variance) was used to test the congruence of middle values of independent groups on the select level of significance $\alpha$. In all the cases the selected level of significance was set at $\alpha=0.05$.

The statistics test $\mathrm{F}$ (Fisher-Snedecor distribution) had in both cases a level greater than 1: in the case of PAHs 343.55 and in the case of pyrene 7.67. However, a statistically significant difference between the concentrations of 1-OHP in the urine of the exposed workers and the concentrations of benzo(a)pyrene in the workplace atmosphere was not found. Next, the non-parametric Spearman correlation test was applied in order to get statistical

Table 2. Distribution of 1-OHP in urine $\left[\mu \mathrm{mol} . \mathrm{mol}^{-1} \mathrm{creatinine}\right]$ before and after exposure

\begin{tabular}{|l|c|c|}
\hline Percentile & Before exposure & After exposure \\
\hline 1 & 0.11 & 0.12 \\
\hline 5 & 0.12 & 0.27 \\
\hline 10 & 0.15 & 0.78 \\
\hline 25 & 0.16 & 0.98 \\
\hline 50 & 0.91 & 2.15 \\
\hline 75 & 1.15 & 3.25 \\
\hline 90 & 1.25 & 3.87 \\
\hline 95 & 1.26 & 4.25 \\
\hline Mean & 0.74 & 2.27 \\
\hline SD & 0.60 & 1.14 \\
\hline Median & 0.91 & 2.15 \\
\hline
\end{tabular}


modeling of the association between the external exposure (PAHs and/or pyrene) and internal dose (1-OHP). Based on the results a strong correlation between the concentration of 1-OHP in urine as an exposure biomarker and the concentration of pyrene $\left(\mathrm{r}_{\mathrm{s}}=0.72\right.$; $\mathrm{p}<0.05)$ or PAH as a sum $\left(\mathrm{r}_{\mathrm{s}}=0.71 ; \mathrm{p}<0.05\right)$ was affirmed.

In order to evaluate the statistical significance of the effect of other determinants of internal dose such as occupational exposure, exposure data were obtained and analyzed for the effect of age, gender, and intensity of smoking.

In terms of gender, representation of women in the both control groups 1 and 2 have been higher compared to the exposed bodies. The aim of the test was to assess significance of the difference between the two bodies. Given the outcome ( $p>0.05)$ difference of 1-hydroxypyrene levels based on gender was not statistically significant.

In case of evaluation of the intensity of smoking, smokers in the exposed group amounted to $59 \%$. Three levels of intensity of exposure according to the number of cigarettes smoked per day were defined (group 1: 1-0 cigarettes, group 2: under 10 cigarettes, and group 3: 10 or more cigarettes per day). The average value of 1-OHP in $\mu$ mol.mol ${ }^{-1}$ creatinine reached 1.90 in nonsmokers group 1 , in group $2-2.40$, and group $3-2.46$. The aim of the testing was to assess significance of the difference between the selected groups. In view of the result $(p>0.05)$ statistically insignificant difference was identified in 1-hydroxypyrene levels depending on the intensity of smoking.

Multidimensional dispersion analysis, which takes into account the impact of PAH exposure or benzo(a)pyrene and pyrene controlled by the intensity of smoking, age and the above mentioned lifestyle parameters proved a high statistical significance $(p<0.001)$ of the effect of occupational exposure to PAH and pyrene on the level of 1-hydroxypyrene in urine. Effects of other factors did not reach statistical significance $(\mathrm{p}>0.05)$.

\section{DISCUSSION AND CONCLUSION}

\section{Pyrene and Benzo(a)pyrene}

The ratio of concentrations of pyrene/benzo(a)pyrene in the samples of the workroom air in the studied plants was different. The lowest value 0.5 was observed in the carbon material plant (plant 2), the ratio 1.0 was observed in the aluminium plant (plant 1), the ratio 3.7 was observed in the bitumen production and asphalting plant (plant 4), and the highest ratio of 6.0 was observed in the pressed rubber products production plant.

These findings are in accordance with data published in literature, where the value of the ratio pyrene/benzo(a)pyrene was in the interval from 1.0-9.5 depending on the occupation. The value of 1.0 was set for the workers in a low-pressure gas plant, ratio 4.8 was set for road paving workers, and the value 9.5 was set for insulation workers (12-14).

\section{1-OHP}

In their work, Barek et al. (15) suggested the metabolite of pyrene 1-OHP as a suitable biomarker for tar exposure measurement. Jongeneelen (16) proved good correlation between the mutagenesis of urine and the content of 1-hydroxypyrene, he also proved the suitability of this bioindicator at PAH exposure in dif- ferent types of work environment. Based on the published works, the concentration of 1-hydroxypyrene in urine is in the interval of: - 1-5 nmol. $\mathrm{l}^{-1}$ at occupationally non-exposed persons;

- $10-50$ nmol. l $^{-1}$ at workers occupationally exposed at aluminium production;

100-10,000 nmol. $\mathrm{l}^{-1}$ at workers occupationally exposed at tar processing (11).

Jongeneelen (17) suggests the value of $3.76 \mu \mathrm{g} \cdot \mathrm{g}^{-1}$ creatinine and/or $1.95 \mu \mathrm{mol} . \mathrm{mol}^{-1}$ creatinine as the biological limit of 1-OHP in the urine of occupationally exposed persons.

The recommended biological limit for 1-hydroxypyrene was exceeded in 11 urine samples taken from the workers in plant 1. The same number of exceeded limits was determined in plant 2 .

At a concentration of $4.0 \mu \mathrm{mol} . \mathrm{mol}^{-1}$ creatinine $\left(7.7 \mu \mathrm{g} . \mathrm{g}^{-1}\right.$ creatinine) based on the regressions between the formation of an illness and the content of 1-OHP in urine, a higher lung carcinoma risk is estimated for the exposed workers in the carbon material production plant (18).

According to Jeng et al. in the workplaces with a high level exposure, 1 -OHP is up to $12.8 \pm 12.9 \mu \mathrm{mol}_{\text {. }} \mathrm{mol}^{-1}$ creatinine (19).

PAH exposure at levels of 1-OHP in urine at $2.3 \mu \mathrm{mol}_{\mathrm{mol}}{ }^{-1}$ creatinine $\left(4.4 \mu \mathrm{g} . \mathrm{g}^{-1}\right.$ creatinine) poses relative risk of lung carcinoma at level 1.3 (12).

In exposed workers, the $1.4 \mu \mathrm{mol} \mathrm{mol}{ }^{-1}$ creatinine was considered as a non-biologically effective value, according to Alegria-Torres (20).

The European Agency for Safety and Health at Work (OSHA) has set the limit of $200 \mu \mathrm{g} \cdot \mathrm{m}^{-3}$ for the sum of PAU in workplace atmosphere. The concentration of 1-OHP, which corresponds with this PAHs concentration as a sum, was estimated at $3.45 \mu \mathrm{g} . \mathrm{g}^{-1}$ creatinine $\left(1.79 \mu \mathrm{mol} . \mathrm{mol}^{-1}\right.$ creatinine $)$.

The British Health and Safety Executive (HSE) has set a hygiene based Biological Monitoring Guidance Value (BMGV) for 1-hydroxypyrene at $4.0 \mu \mathrm{mol} . \mathrm{mol}^{-1}$ creatinine in post-shift samples (21). The value is derived from the 90-percentile of measurements in British companies in various industries with good industrial hygiene practice. The BMGV is not a healthbased limit (22).

Based on the presented results, the suggested biological limit for 1-OHP in the urine of occupationally exposed workers was exceeded in individual cases depending on the type of occupation and on the type of workshop of selected industrial plants.

If we accept the value of 1-OHP $4.0 \mu \mathrm{mol} . \mathrm{mol}^{-1}$ creatinine (7.7 $\mu \mathrm{g} . \mathrm{g}^{-1}$ creatinine) as the value for higher risk of lung carcinoma, then there is a real risk of the development of this illness in some of the workers in the studied plants.

The "dose-response" relation expressing the association between the pyrene exposure in workplace atmosphere and the concentrations of 1-OHP is presented by Pesch et al. (23). Not only the strength, but also the shape of the functional dependence between the exposure biomarker and the exposure data are significant variables for regulation toxicology, mostly for exposure limits application.

The functional dependence between the concentrations of 1-OHP in urine and the exposure to pyrene can be characterized with help of two segments: the first segment in the area of low doses with no apparent association and second segment in the area of higher doses with linear dependence. The interpretation of these findings are as follows: the presence of the first, non-linear 
segment can be caused by high imprecision of data in the area of low exposures. Lower accuracy of setting 1-OHP in the area of low concentrations is acceptable explanation for the missing association between the two variables in this concentration area. Another cause of the missing association in the first segment might be the existence of the so-called toxicokinetic threshold, which was discussed for other chemicals, such as phenanthrene and tetrachlorodibenzodioxin (TCDD). The second segment can be characterized by linear dependence between the two variables; however, the levels of the internal dose do not rise proportionally with the rise of external exposure (factor 0.6$)(23,24)$.

In general, the single PAHs are primarily metabolised into (poly)-hydroxy-PAHs, which are preferentially eliminated by faecal discharge with only a minor fraction by urine. However, pyrene, composed of four aromatic rings, is an exception here, as $90 \%$ of its main metabolite 1-hydroxypyrene is eliminated by urine (25). That is why one of the possible explanations is the activation of other metabolic mechanisms (e.g. diol-epoxide mechanism) rather than only direct detoxification of pyrene to 1-OHP at higher external exposures (26).

\section{Acknowledgements}

We express our deepest thanks to Mr. John J. Barich, US EPA, Seattle, WA, USA and Mrs. Katarina Mahutova, REES, Engineering and Environmental Services, Seattle, WA, USA for taking part in useful decision and giving necessary advices and making language corrections.

\section{Conflict of Interests}

None declared

\section{REFERENCES}

1. Brandt HC, Watson WP. Monitoring human occupational and environmental exposures to polycyclic aromatic compounds. Ann Occup Hyg 2003;47(5):349-78.

2. World Health Organization; International Programme on Chemical Safety. Selected non-heterocyclic polycyclic aromatic hydrocarbons. World Health Organization: Geneva; 1998. (Environmental Health Criteria; 202).

3. IARC Working Group on the Evaluation of Carcinogenic Risks to Humans. Some Traditional Herbal Medicines, Some Mycotoxins, Naphthalene and Styrene. Lyon: IARC Press; 2002. (IARC Monographs on the Evaluation of Carcinogenic Risks to Humans, vol. 82).

4. International Agency for Research on Cancer. Evaluation of the carcinogenic risk of chemicals to humans: polynuclear aromatic compounds. Part 1. Lyon: International Agency for Research on Cancer; 1983. (IARC Monograph; no. 35).

5. Al-Saleh I, Alsabbahen A, Shinwari N, Billedo G, Mashhour A, Al-Sarra $\mathrm{Y}$, et al. Polycyclic aromatic hydrocarbons (PAHs) as determinants of various anthropometric measures of birth outcome. Sci Total Environ. 2013;444:565-78

6. Huang W, Caudill SP, Grainger J, Needham LL, Patterson DG Jr. Levels of 1-hydroxypyrene and other monohydroxy polycyclic aromatic hydrocarbons in children: A study based on U.S. reference range values. Toxicol Letters. 2006;163(1):10-9.

7. Zhang Y, Ding J, Shen G, Zhong J, Wang C, Wei S, et al. Dietary and inhalation exposure to polycyclic aromatic hydrocarbons and urinary excretion ofmonohydroxy metabolites. A controlled case study in Beijing, China. Environ Pollut. 2014;184:515-22.

8. Yamano Y, Hara K, Ichiba M, Hanaoka T, Pan G, Nakadate T. Urinary 1-hydroxypyrene as a comprehensive carcinogenic biomarker of exposure to polycyclic aromatic hydrocarbons: a cross-sectional study of coke oven workers in China. Int Arch Occup Environ Health. 2014;87(7):705-13.

9. Käfferlein HU, Marczynski B, Simon P, Angerer J, Rihs HP, Wilhelm M, et al. Internal exposure to carcinogenic polycyclic aromatic hydrocarbons and DNA damage: a null result in brief. Arch Toxicol. 2012;86(8):131721.

10. National Institute for Occupational Safety and Health. Polynuclear Aromatic Hydrocarbons by HPLC: 5506. Manual of Analytical Methods. 4th ed. Cincinnati: National Institute for Occupational Safety and Health; 1985.

11. Hornung RW, Reed L. Estimation of average concentration in the presence of nondetectable values. Appl Occup Environ Hyg. 1990;5(1):46-51.

12. Tuček M, Bencko V, Volný J, Petanová J. A contribution to the health risk assessment of exposure to exhaust gases in custom officers at border crossing. Čes Prac Lék. 2006;7(2):76-83. (In Czech.)

13. Tuček M, Krýsl S, Maxa K, Tenglerová J. Carcinogenic risk assessment in occupational exposure to polycyclic aromatic hydrocarbons (PAHs). In: The Fifth International Symposium on Biological Monitoring in Occupational and Environmental Health: book of abstracts; 2001 Sep 19-21; Banff, Canada. 2001. p. 17.

14. Singh R, Tuček M, Maxa K, Tenglerová J, Weyand EH. A rapid and simple method for analysis of 1-hydroxypyrene glucuronide: a potential biomarker for polycyclic aromatic hydrocarbon exposure. Carcinogenesis. 1995;16(12):2909-15.

15. Barek J, Bencko V, Cvačka J, Mejstř́k V, Slámová A, Švagrová I, et al. Determination of 1-hydroxypyrene using high-performance liquid chromatography with electrochemical detection. Chem Listy. 1997;91(10):871-76. (In Czech.)

16. Jongeneelen FJ. Benchmark guideline for urinary 1-hydroxypyrene as biomarker of occupational exposure to polycyclic aromatic hydrocarbons. Ann Occup Hyg. 2001;45(1):3-13.

17. Jongeneelen FJ. Biological exposure limit for occupational exposure to coal tar pitch volatiles at cokeovens. Int Arch Occup Environ Health. 1992;63(8):511-6.

18. Buchet JP, Gennart JP, Mercado-Calderon F, Delavignette JP, Cupers L, Lauwerys R. Evaluation of exposure to polycyclic aromatic hydrocarbons in a coke production and a graphite electrode manufacturing plant: assessment of urinary excretion of 1-hydroxypyrene as a biological indicator of exposure. Br J Ind Med. 1992;49(11):761-8.

19. Jeng HA, Pan CH, Lin WY, Wu MT, Taylor S, Chang-Chien GP, et al. Biomonitoring of polycyclic aromatic hydrocarbons from coke oven emissions and reproductive toxicity in nonsmoking workers. J Hazard Mater. 2013;244-245:436-43.

20. Alegría-Torres JA, Barretta F, Batres-Esquivel LE, Carrizales-Yáñez L, Pérez-Maldonado IN, Baccarelli A, et al. Epigenetic markers of exposure to polycyclic aromatic hydrocarbons in Mexican brickmakers: a pilot study. Chemosphere. 2013;91(4):475-80.

21. EH40/2005 Workplace exposure limits. 2nd ed. Sudbury: Health and Safety Executive; 2011.

22. Jongeneelen FJ. A guidance value of 1-hydroxypyrene in urine in view of acceptable occupational exposure to polycyclic aromatic hydrocarbons. Toxicol Lett. 2014;231(2):239-48.

23. Pesch B, Kappler M, Straif K, Marczynski B, Preuss R, Rossbach B, et al. Dose-response modeling of occupational exposure to polycyclic aromatic hydrocarbons with biomarkers of exposure and effect. Cancer Epidemiol Biomarkers Prev. 2007;16(9):1863-73.

24. Popp P. Determination of polycyclic aromatic hydrocarbons in waste water by off-line coupling of solid-phase microextraction with column liquid chromatography. J Chromatogr A. 2000;897(1-2):153-9.

25. Boogard PJ, Sittert NJ. Exposure to polycyclic aromatic hydrocarbons in petrochemical industries by measurement of urinary 1-hydroxypyrene. Occup Environ Med. 1994;51(4):250-8.

26. Hecht SS, Chen M, Yoder A, Jensen J, Hatsukami D, Le C, et al. Longitudinal study of urinary phenanthrene metabolite ratios: effect of smoking on the diol epoxide pathway. Cancer Epidemiol Biomarkers Prev. 2005;14(12):2969-74. 